\title{
Effect of Replacing Beef Fat with Poppy Seed Oil on Quality of Turkish Sucuk
}

\author{
Veli Gök* \\ Faculty of Engineering, Food Engineering Department, Afyon Kocatepe University, Afyonkarahisar, Turkey
}

\begin{abstract}
Sucuk is the most popular dry-fermented meat product. Sucuk has a relatively high fat. Poppy seed oil as animal fat replacer was used in Turkish sucuk and effects of its use on sucuk quality were investigated. There was a significant $(p<0.5)$ treatment $\times$ ripening time interaction for moisture, $\mathrm{pH}(p<0.05)$ and 2-thiobarbituric acid reactive substances (TBARS) values $(p<0.01)$. Increasing poppy seed oil level decreased $(p<0.05)$ TBARS values. Addition of poppy seed oil to the sucuks had a significant effect $(p<0.01)$ on hardness, cohesiveness, gumminess, chewiness and springiness values. Cholesterol content of sucuks decreased $(p<0.05)$ with poppy seed oil addition. Using pre-emulsified poppy seed oil as partial fat replacer in Turkish sucuk decreased cholesterol and saturated fatty acid content, but increased polyunsaturated fatty acids. Poppy seed oil as partial animal fat replacer in Turkish sucuk may have significant health benefits.
\end{abstract}

Key words: poppy seed oil, turkish sucuk, fat replacer, cholesterol reduction, polyunsaturated fatty acids

Received December 31, 2014 / Revised March 19, 2015 / Accepted March 23, 2015

\section{Introduction}

Sucuk is the most popular dry-fermented meat product produced in Turkey. It can be produced from beef and water buffalo meat and it may contain beef fat, sheep tail fat, salt, sugar, nitrite, nitrate and/or nitrite/nitrate and various spices (Gökalp et al., 1999). Sucuk has relatively high fat content ranging from 30 to $40 \%$ and fat is easily recognizable in its slices (Yıldiz-Turp and Serdaroglu, 2008). Fat is a major contributor of flavor, texture, mouth feel, juiciness and overall acceptability of the meat products (Muguerza et al., 2002). However, unfortunately, high amount of fat in meat products is associated with high amount of saturated fatty acids and cholesterol in meat products. Therefore, meat products are blamed for causing hypertension, obesity, cardiovascular diseases and coronary health diseases (Özvural and Vural, 2008). Moreover, high-fat intake also increases risk of some cancers, namely colon, breast and prostate (Chizzolini et al., 1999). To this end, health organizations all over the world highly recommend limiting the intake of saturated fatty acids and cholesterol (NCEP, 1988).

*Corresponding author: Velı gök, Faculty of Engineering, Food Engineering Department, Afyon Kocatepe University, 03200 Gazligol Yolu, Afyonkara- hisar, Turkey. Tel: +90-272-22281423, Fax: +90-272-2228-1422, E-mail: vgok@aku.edu.tr
The demand for healthy meat products has recently increased considerably and the food industry has been trying to develop or modify meat products by decreasing amount of animal fat (Choi et al., 2010; Gök et al., 2011; Yıldız-Turp and Serdaroglu, 2008). Several studies have focused on reducing the fat and cholesterol content of meat products (Ilıkkan et al., 2009; Kayaardı and Gök, 2004).

Oilseeds are major source of fat, protein, and carbohydrate and they have potential to be used in nutraceuticals and functional foods (Bozan and Temelli, 2008). Papaver somniferum (poppy) seeds are very popular in Europe and Turkey and are extensively used in bakery products (Erinc et al., 2009). Poppy seed oil (PSO) contains 73\% linoleic, $10 \%$ palmitic, and $13 \%$ oleic acid as major fatty acids (Gök et al. 2011; Nergiz and Otles, 1994). The rich polyunsaturated fatty acid content of poppy seed oil makes it a viable alternative to be used in reduced fat meat products. Therefore, the goals of this study were to produce Turkish sucuk using poppy seed oil as partial animal fat replacer and to determine chemical, textural, color and sensory properties of the product.

\section{Materials and Method}

\section{Sucuk formulation and preparation}

Meat used in the study came from 3-year old mature 
cows and beef fat was obtained from Portakalogllları Meat Corporation (Afyonkarahisar, Turkey). Poppy seed oil was supplied locally (Arpacıoğlu Haşhaş Ezmecilik Company, Turkey) and other ingredients were also purchased locally. The lean meat was separated from visible fat, tendons and other connective tissues. The lean meat and frozen beef fat were minced in a cuter (Germany) to a particle size of about $3 \mathrm{~mm}$ and subsequently mixed in a mixer. Sucuk formulation contained $9 \mathrm{~kg}$ meat (10\% fat, wet basis), $1.1 \mathrm{~kg}$ beef fat, $0.20 \mathrm{~kg} \mathrm{NaCl}, 0.16 \mathrm{~kg}$ garlic, $0.04 \mathrm{~kg}$ sucrose, $0.07 \mathrm{~kg}$ hot red pepper, $0.04 \mathrm{~kg}$ sweet red pepper, $0.08 \mathrm{~kg}$ black pepper, $0.080 \mathrm{~kg}$ cumin, $0.02 \mathrm{~kg}$ allspice, 300 ppm $\mathrm{NaNO}_{3}$ and 150 ppm $\mathrm{NaNO}_{2}$ and $0.002 \mathrm{~g}$ starter culture (Lactobacillus plantarum and Staphylococcus carnosus, Bactoferm TM T-D-66, CHR HANSEN, Germany).

The fat content of the first batch (control) was adjusted to $20 \%$ by adding beef fat. Poppy seed oil was added to the next three treatments of sucuk dough as pre-emulsified fat (PEF) with sodium caseinate (American Casein Company, USA), by replacing 25, 50 and $75 \%$ of beef fat, respectively. To produce the poppy seed oil emulsion, 1 part of sodium caseinate and 8 parts of hot water $(75$ ${ }^{\circ} \mathrm{C}$ ) were mixed for $2 \mathrm{~min}$ in a blender. The mixture was emulsified with 10 parts of poppy seed oil for $3 \mathrm{~min}$. The resultant mixture and frozen fat were ground through 12mm plate (Esmak Machine Co, Turkey). Sucuk dough coming from the grinding machine was refrigerated at $4^{\circ} \mathrm{C}$ for $8 \mathrm{~h}$ and was thoroughly mixed in a bowl cutter (Germany) at 10-12 rpm for $2 \mathrm{~min}$. The mixture was stuffed into the natural cow intestine casings of $38-40 \mathrm{~mm}$ in diameter. Sucuk samples were held in a tempering room (10-12 ${ }^{\circ} \mathrm{C}$ and $70-75 \%$ relative humidity) for $12 \mathrm{~h}$. Then, they were ripened in an incubation room (Germany) for $12 \mathrm{~d}$ with the following protocol: $2 \mathrm{~d}$ at $90 \%$ relative humidity (RH) and $28^{\circ} \mathrm{C} ; 2 \mathrm{~d}$ at $85 \% \mathrm{RH}$ and $24^{\circ} \mathrm{C} ; 2 \mathrm{~d}$ at $80 \% \mathrm{RH}$ and $22^{\circ} \mathrm{C} ; 2 \mathrm{~d}$ at $75 \% \mathrm{RH}$ and $20^{\circ} \mathrm{C} ; 2 \mathrm{~d}$ at $70 \%$ $\mathrm{RH}$ and $18^{\circ} \mathrm{C} ; 2 \mathrm{~d}$ at $65 \% \mathrm{RH}$ and $18^{\circ} \mathrm{C}$.

\section{Proximate analysis}

Moisture, fat (ether-extractable) and $\mathrm{pH}$ value were determined according to AOAC (1990) procedures on the day 0 (initial), 4, 7 and 12 of ripening. The number of replication was three for the all the properties measured.

\section{Lipid oxidation analysis}

The 2-thiobarbituric acid reactive substances (TBARS) test was used to assess extent of lipid oxidation throughout ripening. The TBARS test was performed as described by Gök et al. (2008).

\section{Texture profile analysis}

For texture profile analysis (TPA), sucuk samples having diameter of $38 \mathrm{~mm}$ were cut into cylinders with height of $20 \mathrm{~mm}$, and wrapped with plastic, and held at room temperature for equilibration and were then compressed twice with $50 \%$ deformation with a stainless compression probe (Bozkurt and Bayram, 2006). TPA tests were performed using a Texture Analyzer (TA-XT plus, Stable Micro Systems Ltd., UK).

The stainless compression probe of $5 \mathrm{~cm}$ in diameter, mounted to a $50 \mathrm{~kg}$ load cell, was used for texture analyses at a crosshead speeds of $1 \mathrm{~mm} / \mathrm{s}$ (pretest), $5 \mathrm{~mm} / \mathrm{s}$ (test), and $5 \mathrm{~mm} / \mathrm{s}$ (post test); time between two compressions, $5.0 \mathrm{~s}$; trigger type, auto-20 g; and data acquisition rate, 200 point/s. The TPA parameters were obtained from Texture Expert software V.1.22 attached to the Texture Analyzer (Stable Micro Systems). They were determined from force-time curves as described by Bourne (1978): Hardness (resistance at maximum compression of first bite to deform the sample; peak force of the first compression cycle in $\mathrm{N}$ ), cohesiveness (extent to which sample could be deformed prior to rupture; positive force ratio of the second compression area to the first compression area $\left(\mathrm{A}_{2} / \mathrm{A}_{1}\right)$, Gumminess (force necessary to disintegrate a semi-solid sample for swallowing, it is the multiplication of hardness and cohesiveness, N), springiness (a measure of how well a product physically springs back after it has been deformed during first compression, ability of sample to recover to its original height after the deforming force was removed, $\mathrm{mm}$ ), chewiness (the energy need to chew a solid sample to a steady state of swallowing hardness multiplied by cohesiveness multiplied by springiness in, Nmm)

\section{Color measurement}

Color measurements (CIE $\left.L^{*}, a^{*}, b^{*}\right)$ were taken with a colorimeter (Minolta CR 400, Japan). The samples were placed into petri dishes before taking the readings; no gap existed between the sample and the petri dish lid during measurement. The lens of the colorimeter was placed against the petri dish lid, and six readings were averaged.

\section{Cholesterol content}

Total cholesterol content of sucuks was determined as given by Naeemi et al. (1995). Briefly, $1 \mathrm{~g}$ of sucuk sample was hydrolyzed with $5 \mathrm{~mL}$ saturated methanolic $\mathrm{KOH}$ and then, $5 \mathrm{~mL}$ of cyclohexane was added and the mix- 
ture was centrifuged at 2,000 rpm for $2 \mathrm{~min}$. The resultant upper phase was analyzed using a gas chromatograph (Agilent 6890, Germany) fitted with a Ultra performance capillary column $(25 \mathrm{~m} \times 0.32 \mathrm{~mm} \times 0.52 \mu \mathrm{m}$ film thickness, HP 5080-8853) under the following operating conditions: carrier gas, hydrogen, at a flow rate of $2.0 \mathrm{~mL} /$ min; oven temperature 180 to $280^{\circ} \mathrm{C}$ for $10 \mathrm{~min}$; injector temperature of $290^{\circ} \mathrm{C}$; and flame ionization detector at $300^{\circ} \mathrm{C}$ (Gök et al., 2011).

\section{Fatty acid composition}

Fat extraction and fatty acids methyl esters (FAME) were determined using the AOAC (1990) method. Analysis of the FAME was accomplished using Agilent 6890 gas chromatograph equipped with flame-ionization detector (FID) on a split injector and a fused-silica capillary column (Supelco (USA) SP 2380, $60 \mathrm{~m} \times 0.25 \mathrm{~mm}$ i.d., $0.2 \mathrm{~mm}$ film thickness). The column was isothermally $\left(180^{\circ} \mathrm{C}\right)$ operated, injector and detector were kept at 250 ${ }^{\circ} \mathrm{C}$ and the oven temperature program was at $120^{\circ} \mathrm{C}$ for 1 min, and increased to $240^{\circ} \mathrm{C}$ at a rate of $6^{\circ} \mathrm{C} / \mathrm{min}$ and then was kept constant $\left(240^{\circ} \mathrm{C}\right)$ for $15 \mathrm{~min}$. The flow rate of carrier gas (helium) was $30 \mathrm{~mL} / \mathrm{min}$.

\section{Sensory evaluation}

An experienced ten member trained sensory panel evaluated sucuk samples. Panel members were either faculty or graduate students of the Food Engineering Department of Afyon Kocatepe University. Four training sessions were held to familiarize the panelists with the sucuk characteristics to be evaluated and the scale to be used. The samples were served to panelists in artificial light (incandescent) at room $\left(22^{\circ} \mathrm{C}\right)$ temperature in a random order all together. Unsalted crackers and deionized rinse water were given to panelists between individual samples. A continuous scale between 1.0 and 9.0 was used for the evaluation of the each attribute. Evaluating only four sucuks per session and two sessions per day was scheduled to prevent fatigue (total nine sessions). Panelists evaluated the samples for appearance ((visual impression of the products' surface - shape, color), cut appearance (visual impression at the cross section - particle size and uniformity, glistening of fat, stickiness)); Texture (perceived firmness in the mouth); Color (red color intensity); Flavor (intensity of poppy oil flavor), and expressed their overall acceptability. The hedonic scale was as follows: 1-3 (not acceptable), 4-5 (fairly acceptable), 6-7 good (acceptable) and 8-9 very good (Gök et al., 2008).

\section{Statistical analysis}

Design of the experimental part was randomized having 4 (treatment levels) $\times 4$ (ripening times) factorial structure. Treatments included control $\left(\mathrm{T}_{1}, 100 \%\right.$ all animal fat $), \mathrm{T}_{2}$ (25\% pre-emulsified poppy seed oil $/ 75 \%$ animal fat), $\mathrm{T}_{3}$ (50\% pre-emulsified poppy seed oil $/ 50 \%$ animal fat), $\mathrm{T}_{4}$ (75\% pre-emulsified poppy seed oil $/ 25 \%$ animal fat). Storage times were $0,4,7$, and $12 \mathrm{~d}$. PROC MIXED procedure was used to analyze the data and means were separated when significant $(p<0.05)$ using the Fisher's protected least significant difference test (SAS, 2001). The treatment structure was completely randomized with 3 replications.

\section{Results and Discussion}

There was a significant $(p<0.05)$ treatment $\times$ ripening time interaction for $\mathrm{pH}$. During the first $7 \mathrm{~d}$ of ripening, the $\mathrm{pH}$ values of all sucuk decreased due to the production of lactic acid by lactic acid bacteria. For a given treatment, $\mathrm{pH}$ showed a decrease from day 0 to day 7 of ripening, however, it exhibited an increasing trend afterwards (Table 1). The decline in the $\mathrm{pH}$ can be attributed to lactic acid produced in carbohydrate breakdown during fermentation (Muguerza et al., 2002), while the increase in the $\mathrm{pH}$ can be explained by nitrogenous compounds formed in proteolysis during fermentation (Aksu and Kaya, 2004).

There was a significant $(p<0.01)$ treatment $\mathrm{x}$ ripening time interaction $(p<0.01)$ for moisture content (Table 1). For a given treatment, moisture decreased with increased ripening time. The percentage decrease in moisture content was $37 \%$ in control (T1), whereas it was only $33 \%$ in T4. Caseinate used in pre-emulsification of ground poppy seed oil might have increased water holding capacity of sucuks. Similarly, Mallika and Prabhakar (2011) reported increased water holding capacity for the sausages containing milk co-precipitates. Moreover Muguerza et al. (2001) used pre-emulsified olive oil in Spanish fermented sausages as partial animal fat replacer and declared higher water holding capacity for these samples as compared to that of control.

Fat contents of samples are shown in Table 1. There was a significant $(p<0.01)$ treatment $\times$ ripening time interaction for fat content. Fat content increased with ripening time (Table 1) due to water loss during the drying process. Similarly, Soyer et al. (2005) reported increases in the fat content of sucuks over ripening time. All the treatments, had fat content of less than $40 \%$, which is the per- 
Table 1. Least square means values for treatment $x$ ripening time interaction on, $\mathrm{pH}$, moisture, fat, and TBARS content of sucuks $(\mathbf{n}=\mathbf{3})^{*}$

\begin{tabular}{lcccc}
\hline \hline Source of variation & $\mathrm{pH}$ & Moisture (\%) & Fat (\%) & TBARS \\
\hline Treatment $\times$ Ripening Time & & & & \\
0 T1 & $6.07 \pm 0.048$ & $59.01 \pm 0.43$ & $21.18 \pm 0.18$ & $0.33 \pm 0.018$ \\
0 T2 & $6.06 \pm 0.039$ & $60.04 \pm 0.56$ & $22.10 \pm 0.24$ & $0.32 \pm 0.022$ \\
0 T3 & $6.05 \pm 0.034$ & $60.28 \pm 0.65$ & $22.39 \pm 0.20$ & $0.30 \pm 0.020$ \\
0 T4 & $6.04 \pm 0.32$ & $60.50 \pm 0.67$ & $22.90 \pm 0.26$ & $0.36 \pm 0.032$ \\
4 T1 & $4.96 \pm 0.29$ & $49.16 \pm 0.42$ & $26.86 \pm 0.25$ & $0.47 \pm 0.038$ \\
4 T2 & $4.93 \pm 0.26$ & $49.93 \pm 0.36$ & $27.23 \pm 0.27$ & $0.44 \pm 0.035$ \\
4 T3 & $4.89 \pm 0.24$ & $50.49 \pm 0.54$ & $27.91 \pm 0.30$ & $0.40 \pm 0.032$ \\
4 T4 & $4.85 \pm 0.27$ & $51.02 \pm 0.51$ & $28.05 \pm 0.31$ & $0.39 \pm 0.026$ \\
7T1 & $4.90 \pm 0.25$ & $44.27 \pm 0.43$ & $30.06 \pm 0.26$ & $0.81 \pm 0.042$ \\
7 T2 & $4.86 \pm 0.22$ & $44.93 \pm 0.41$ & $30.83 \pm 0.24$ & $0.75 \pm 0.038$ \\
7 T3 & $4.81 \pm 0.19$ & $45.75 \pm 0.39$ & $31.15 \pm 0.31$ & $0.71 \pm 0.034$ \\
7 T4 & $4.77 \pm 0.16$ & $46.37 \pm 0.48$ & $31.67 \pm 0.33$ & $0.70 \pm 0.032$ \\
12 T1 & $5.06 \pm 0.31$ & $37.40 \pm 0.24$ & $37.70 \pm 0.27$ & $0.96 \pm 0.054$ \\
12 T2 & $5.00 \pm 0.26$ & $38.24 \pm 0.27$ & $37.92 \pm 0.34$ & $0.93 \pm 0.048$ \\
12 T3 & $4.96 \pm 0.25$ & $39.81 \pm 0.31$ & $38.30 \pm 0.30$ & $0.89 \pm 0.045$ \\
12 T4 & $4.93 \pm 0.18$ & $40.36 \pm 0.34$ & $38.76 \pm 0.36$ & $0.83 \pm 0.034$ \\
LSD** & 0.03 & 0.40 & 0.26 & 0.03 \\
\hline
\end{tabular}

T1, Control 100\% all animal fat; T2, 25\% pre-emulsified poppy seed oil/75\% animal fat; T3, 50\% pre-emulsified poppy seed oil/ $50 \%$ animal fat; T4, 75\% pre-emulsified poppy seed oil $/ 25 \%$ animal fat.

*Values are given as mean \pm standard deviation from triplicate determinations.

$* *$ LSD, least significant difference (calculated at $\alpha=0.05$ ); $n$, replication number.

missible level in Turkish Food Codex (2000).

TBARS content is lipid oxidation markers in meat and meat products (Shahidi et al., 1987). The TBARS values of the sucuk samples are shown in Table 1 . There was a significant $(p<0.01)$ treatment $\times$ storage time interaction for TBARS. The TBARS values of the control samples increased about 2 fold (Table 1), nevertheless the increase was only limited to 1.3 fold for T4. Our results are not in agreement with the result of Il1kkan et al. (2009) who reported higher TBARS values in Turkish sucuks having hazelnut as partial animal fat replacer. Lower TBARS values with poppy seed oil addition in this study can be attributed to the antioxidant activity of the $\alpha$-tocopherol, a naturally found compound in poppy seed oil (Erinç et al., 2009). Moreover, Shahidi (2000) reported that phenolic compounds found in seed oils might have a protective effect on oxidative rancidity. Similarly, poppy seed oil was reported to have more oxidative stability than safflower or flax oil (Bozan and Temelli, 2008). In addition, Severini et al. (2003) reported lower TBARS values in fermented sausages having olive oil as partial fat replacer stored than control samples for $30 \mathrm{~d}$.

Addition of poppy seed oil to the sucuks had a significant effect $(p<0.01)$ on hardness (Table 2$)$. T1 had higher $(p<0.05)$ hardness, cohesiveness, gumminess, chewiness but lower $(p<0.05)$ springiness than any other treatment. Poppy seed oil addition to sucuks decreased hardness, which is a significant indicator of palatability. Similarly Yildız-Turp and Serdaroglu (2008) reported soft texture for sucuk samples having hazelnut oil as fat replacer. On the other hand, Bloukas et al. (1997) detected no difference in texture for sausages having olive oil as fat replacer. Hardness and cohesiveness increased with decreased moisture content in this study. Similarly, Rongrong et al. (1998) reported increased hardness and cohesiveness for smoked sausages as their moisture content decreased. Springiness is related to elastic properties of sucuk. T4, having highest poppy seed oil and moisture content, was the most elastic one $(p<0.05)$. To this end, Bozkurt and Bayram (2006), reported decreased elasticity of sucuk during ripening period and attributed this decrease to removal of water.

Treatment $\times$ ripening time interaction was only significant $(p<0.05)$ for CIE a*(redness) (Table 3$)$. For a given treatment, redness increased with ripening time, which is in line with Erçoşkun et al. (2010), who reported increased redness with ripening time for sucuks.

The dehydration during the ripening period may also affect the light scatter properties on the surface of the product (Bozkurt, 2006; Erçoşkun et al., 2010). Lightness $\left(\mathrm{L}^{*}\right)$ values had an increasing trend while yellowness $\left(\mathrm{b}^{*}\right.$ values) had a decreasing trend with ripening time. The decrease in CIE $b^{*}$ values with ripening time can be explained by formation of brown melanoids, product of 
Table 2. Textural parameters of sucuk $(n=3)^{*}$

\begin{tabular}{cccccc}
\hline \hline Treatment & Hardness $(\mathrm{N})$ & Cohesiveness & Gumminess $(\mathrm{N})$ & Springiness $(\mathrm{mm})$ & Chewiness $(\mathrm{N} \times \mathrm{mm})$ \\
\hline T1 & $73.60 \pm 2.42$ & $0.33 \pm 0.01$ & $24.30 \pm 1.71$ & $7.57 \pm 0.05$ & $184.03 \pm 10.34$ \\
T2 & $59.72 \pm 1.89$ & $0.31 \pm 0.009$ & $18.22 \pm 1.39$ & $7.85 \pm 0.02$ & $142.92 \pm 8.32$ \\
T3 & $57.22 \pm 1.35$ & $0.28 \pm 0.007$ & $15.74 \pm 1.33$ & $7.97 \pm 0.05$ & $125.41 \pm 4.82$ \\
T4 & $48.07 \pm 1.17$ & $0.25 \pm 0.005$ & $11.78 \pm 1.22$ & $8.15 \pm 0.03$ & $95.99 \pm 3.56$ \\
LSD** & 3.45 & 0.026 & 3.05 & 0.15 & 20.44 \\
\hline
\end{tabular}

T1, Control 100\% all animal fat; T2, 25\% pre-emulsified poppy seed oil/75\% animal fat; T3, 50\% pre-emulsified poppy seed oil/50\% animal fat; T4, 75\% pre-emulsified poppy seed oil $/ 25 \%$ animal fat.

*Values are given as mean \pm standard deviation from triplicate determinations.

**LSD, least significant difference (calculated at $\alpha=0.05$ ); n, replication number.

Table 3. Least square means values for treatment, ripening time, treatment $x$ ripening time interaction on instrumental color $\left(\right.$ CIE $\left.L^{*}, a^{*}, b^{*}\right)$ of sucuk $(n=3) *$

\begin{tabular}{cccc}
\hline \hline Source of variation & $\mathrm{L}^{*}$ & $\mathrm{a}^{*}$ & $\mathrm{~b}^{*}$ \\
\hline Ripening time (d) & $38.07 \pm 1.85$ & $19.46 \pm 0.99$ & $17.13 \pm 2.01$ \\
12 & $43.55 \pm 1.41$ & $20.88 \pm 1.35$ & $15.23 \pm 1.95$ \\
P-value & $<.0001$ & $<.0001$ & $<.0001$ \\
LSD & 0.45 & - & 0.28 \\
\hline Treatment & & & $13.66 \pm 1.11$ \\
T1 & $38.70 \pm 3.72$ & $18.60 \pm 0.75$ & $15.58 \pm 0.82$ \\
T2 & $40.41 \pm 2.88$ & $19.84 \pm 0.47$ & $16.76 \pm 1.44$ \\
T3 & $41.36 \pm 3.25$ & $20.82 \pm 0.80$ & $18.71 \pm 1.08$ \\
T4 & $42.78 \pm 2.88$ & $21.41 \pm 1.22$ & $<.0001$ \\
P-value & $<.0001$ & $<.0001$ & 0.40 \\
LSD & 0.65 & - & $14.62 \pm 0.17$ \\
0T1 & & & $16.28 \pm 0.19$ \\
0T2 & $35.91 \pm 0.38$ & $17.97 \pm 0.25$ & $18.01 \pm 0.32$ \\
0T3 & $37.93 \pm 0.42$ & $19.44 \pm 0.22$ & $19.61 \pm 0.52$ \\
0T4 & $38.56 \pm 0.56$ & $20.13 \pm 0.24$ & $12.71 \pm 0.15$ \\
12T1 & $40.29 \pm 0.77$ & $20.30 \pm 0.26$ & $14.88 \pm 0.16$ \\
12T2 & $41.89 \pm 0.65$ & $19.24 \pm 0.20$ & $15.52 \pm 0.19$ \\
12T3 & $42.91 \pm 0.82$ & $20.23 \pm 0.14$ & $17.82 \pm 0.26$ \\
12T4 & $44.16 \pm 0.91$ & $21.52 \pm 0.22$ & 0.07 \\
P-value & $45.27 \pm 0.95$ & $22.53 \pm 0.52$ & -
\end{tabular}

T1, Control $100 \%$ all animal fat; T2, 25\% pre-emulsified poppy seed oil/ $/ 75 \%$ animal fat; T3, 50\% pre-emulsified poppy seed oil $/ 50 \%$ animal fat; T4, $75 \%$ pre-emulsified poppy seed oil $/ 25 \%$ animal fat.

*Values are given as mean \pm standard deviation from triplicate determinations.

**LSD, least significant difference (calculated at $\alpha=0.05$ ); $\mathrm{n}$, replication number.

browning reactions (Bozkurt and Bayram, 2006). On a given ripening day, control samples (T1) had lower CIE $\mathrm{L}^{*}, \mathrm{a}^{*}$, and $\mathrm{b}^{*}$ values than any other poppy seed oil containing samples (Table 3). Similarly, Ilıkkan et al. (2009) reported high CIE $\mathrm{L}^{*}, \mathrm{a}^{*}$, and $\mathrm{b}^{*}$ values for sucuk samples having hazelnut oil as fat replacer.

Tables 4 illustrates cholesterol content and fatty acid composition of treatments. Cholesterol content of sucuks decreased $(p<0.05)$ as poppy seed oil amount increased. The cholesterol contents decreased 22,49 , and $70 \%$ for $\mathrm{T} 2$, T3, and T4, respectively, which coincides with Choi et al.
(2010) who reported lower cholesterol contents in reducedfat frankfurter formulated with vegetables oils and rice bran fiber. Similarly, Yıldiz-Turp and Serdaroglu (2008) determined lower cholesterol values for Turkish sucuks having $15-50 \%$ pre-emulsified hazelnut oil as animal fat replacers. These findings are very significant because American Heart Association (2004) have recommended less than $300 \mathrm{mg}$ cholesterol intake per day due to cholesterol's close relationship with cardiovascular and coronary heart diseases.

PSO addition as animal fat replacer changed $(p<0.05)$ 
Table 4. Cholesterol content (mg/g samples) and fatty acid composition (\%) of sucuks and poppy seed oil (n=3)*

\begin{tabular}{|c|c|c|c|c|c|c|}
\hline \multirow{2}{*}{ Parameters } & \multicolumn{5}{|c|}{ Treatments } & \multirow{2}{*}{$\mathrm{LSD}^{* *}$} \\
\hline & PSO* & T1 & $\mathrm{T} 2$ & T3 & $\mathrm{T} 4$ & \\
\hline Cholesterol (mg/100 g) & - & $86.04 \pm 2.98$ & $66.80 \pm 1.96$ & $43.69 \pm 1.56$ & $25.38 \pm 1.34$ & 2.88 \\
\hline \multicolumn{7}{|c|}{ Fatty acid composition (\%) } \\
\hline Lauric C14:0 & - & $0.10 \pm 0.028$ & $0.08 \pm 0.014$ & $1.16 \pm 0.042$ & $1.12 \pm 0.056$ & 0.11 \\
\hline Miristic C14:0 & $0.11 \pm 0.008$ & $2.61 \pm 0.042$ & $2.00 \pm 0.071$ & $1.25 \pm 0.057$ & $0.25 \pm 0.014$ & 0.14 \\
\hline Pentadecanoic C15:0 & - & $1.24 \pm 0.039$ & $0.63 \pm 0.031$ & $0.24 \pm 0.025$ & $0.12 \pm 0.011$ & 0.09 \\
\hline Palmitic C16:0 & $8.07 \pm 0.12$ & $24.17 \pm 0.25$ & $21.56 \pm 0.19$ & $15.23 \pm 0.14$ & $14.38 \pm 0.09$ & 0.24 \\
\hline Palmitoleic & - & $2.02 \pm 0.044$ & $2.47 \pm 0.048$ & $1.46 \pm 0.034$ & $1.67 \pm 0.039$ & 0.18 \\
\hline Margaric C17:0 & - & $2.75 \pm 0.056$ & $2.21 \pm 0.045$ & $0.85 \pm 0.016$ & $0.82 \pm 0.013$ & 0.12 \\
\hline Stearic C18:0 & $3.61 \pm 0.025$ & $23.97 \pm 0.19$ & $17.89 \pm 0.13$ & $11.32 \pm 0.06$ & $10.63 \pm 0.03$ & 0.21 \\
\hline Oleic C18:1 & $24.28 \pm 0.12$ & $36.08 \pm 0.39$ & $33.28 \pm 0.31$ & $29.17 \pm 0.25$ & $23.31 \pm 0.21$ & 0.46 \\
\hline Linoleic C18:2 & $60.53 \pm 0.23$ & $5.79 \pm 0.08$ & $18.35 \pm 0.19$ & $36.90 \pm 0.28$ & $41.23 \pm 0.32$ & 0.45 \\
\hline Linolenic C18:3 & $3.23 \pm 0.021$ & $0.56 \pm 0.05$ & $0.88 \pm 0.09$ & $1.97 \pm 0.14$ & $2.31 \pm 0.25$ & 0.14 \\
\hline Arachidic C20:0 & - & $0.78 \pm 0.029$ & $0.65 \pm 0.023$ & $0.45 \pm 0.015$ & $0.23 \pm 0.009$ & 0.08 \\
\hline SFA & $11.78 \pm 0.02$ & $55.55 \pm 0.48$ & $45.02 \pm 0.41$ & $30.50 \pm 0.34$ & $27.48 \pm 0.28$ & 0.76 \\
\hline MUFA & $24.45 \pm 0.015$ & $38.10 \pm 0.25$ & $35.75 \pm 0.23$ & $30.63 \pm 0.18$ & $24.98 \pm 0.12$ & 0.45 \\
\hline PUFA & $63.76 \pm$ & $6.35 \pm 0.11$ & $19.23 \pm 0.19$ & $38.87 \pm 0.29$ & $43.54 \pm 0.37$ & 0.44 \\
\hline UFA & $88.21 \pm 0.41$ & $44.45 \pm 0.27$ & $54.98 \pm 0.43$ & $69.50 \pm 0.51$ & $68.52 \pm 0.44$ & 0.46 \\
\hline SFA/UFA & $0.13 \pm 0.005$ & $1.25 \pm 0.023$ & $0.82 \pm 0.018$ & $0.44 \pm 0.012$ & $0.40 \pm 0.010$ & 0.02 \\
\hline PUFA/SFA & $5.21 \pm 0.007$ & $0.11 \pm 0.012$ & $0.43 \pm 0.021$ & $1.27 \pm 0.031$ & $1.58 \pm 0.038$ & 0.03 \\
\hline
\end{tabular}

T1, Control 100\% all animal fat; T2, 25\% pre-emulsified poppy seed oil/75\% animal fat; T3, 50\% pre-emulsified poppy seed oil $/ 50 \%$ animal fat; T4, $75 \%$ pre-emulsified poppy seed oil $/ 25 \%$ animal fat.

*Values are given as mean \pm standard deviation from triplicate determinations.

**LSD, least significant difference (calculated at $\alpha=0.05$ ); n, replication number; SFA, saturated fatty acids; MUFA, monounsaturated fatty acids; PUFA, polyunsaturated fatty acids; UFA, unsaturated fatty acids.

the fatty acid composition of sucuks. Addition of PSO decreased $(p<0.05)$ saturated fatty acid concentration (SFA), but increased $(p<0.05)$ polyunsaturated fatty acid (PUFA) concentration (Table 4). Similarly, Ilıkkan et al. (2009) reported decreased SFA, but increased PUFA values in Turkish sucuks with hazelnut oil as animal fat replacers. In this study, PSO addition decreased $(p<0.05)$ miristic, pentadecanoic, palmitic, palmitoleic, margaric, stearic, oleic and arachidic acid, but increased $(p<0.05)$ lauric, linoleic and linolenic acid. The percentage of an important fatty acid, linoleic acid, was $5.79 \%$ for $\mathrm{T} 1$, but increased to $8.35 \%, 36.90 \%$ and $41.23 \%, \mathrm{~T} 2, \mathrm{~T} 3, \mathrm{~T} 4$, respectively, which is very significant because health benefits of oils rich in linoleic acid, like corn or safflower oils, in lowering serum cholesterol levels were reported by several researchers (Belury et al., 2002; Bozan and Temelli, 2008; Simopoulos, 1997).

Polyunsaturated fatty acids decrease plasma cholesterol levels; also they have potential benefits including reduced blood pressure and cardiac arrhythmias (Wijendran and Hayes, 2004). The ratio of PUFA to SFA was 0.11 in T1, however, it became 4, 11, and 14-fold for T2, T3, and T4, respectively. $\mathrm{T} 3$ and $\mathrm{T} 4$ treatments in this study exceed the PUFA/SFA ratio of 0.45 , which has been recommen- ded by The Committee on the Medical Aspects of Food Policy (COMA 1984). The SFA/UFA ratios decreased 34, 65 , and $68 \%$ for $\mathrm{T} 2, \mathrm{~T} 3, \mathrm{~T} 4$, respectively, as compared to T1. This is in line with the results of Choi et al. (2010) who reported decreased SFA/UFA ratios in frankfurters having vegetable oil as partial animal replacer.

The use of poppy oil in the formulation of Turkish Sucuk had a significant $(p<0.05)$ effect on appearance, texture, color, flavor and overall acceptability (Table 5). The highest appearance, texture, color, and overall acceptability scores were observed in T3. T2 had the highest flavor score and panelists did not like the texture of $\mathrm{T} 4$ which might be attributed to soft texture and mushiness associated with increasing poppy seed oil content. Similarly, Yıldiz-Turp and Serdaroglu (2008) reported reduced texture score for Turkish sucuk as amount of vegetable oil (hazelnut) increased. Reduced flavor scores with increased poppy seed oil amount in this study can be explained by undesirable odor of poppy seed oil. Except for flavor, panelists preferred $\mathrm{T} 3$ treatment to any other treatments.

\section{Conclusion}

Using pre-emulsified poppy seed oil as partial fat repla- 
Table 5. Sensory properties of sucuk $(n=3) *$

\begin{tabular}{cccccc}
\hline \hline Treatment & Appearance & Texture & Color & Flavor & Overall acceptability \\
\hline T1 & $8.1 \pm 0.46$ & $7.5 \pm 0.38$ & $7.7 \pm 0.34$ & $7.7 \pm 0.35$ & $7.85 \pm 0.54$ \\
T2 & $7.8 \pm 0.38$ & $7.9 \pm 0.41$ & $7.95 \pm 0.37$ & $8.3 \pm 0.38$ & $7.65 \pm 0.59$ \\
T3 & $8.3 \pm 0.48$ & $8.3 \pm 0.43$ & $8.3 \pm 0.46$ & $7.55 \pm 0.40$ & $8.35 \pm 0.62$ \\
T4 & $7.2 \pm 0.24$ & $6.25 \pm 0.19$ & $6.9 \pm 0.23$ & $6.5 \pm 0.21$ & $6.7 \pm 0.32$ \\
LSD $^{* *}$ & 0.39 & 0.35 & 0.36 & 0.31 & 0.26 \\
\hline
\end{tabular}

T1, Control $100 \%$ all animal fat; T2, 25\% pre-emulsified poppy seed oil/75\% animal fat; T3, 50\% pre-emulsified poppy seed oil $/ 50 \%$ animal fat; T4, $75 \%$ pre-emulsified poppy seed oil $/ 25 \%$ animal fat.

*Values are given as mean \pm standard deviation from triplicate determinations.

**LSD, least significant difference (calculated at $\alpha=0.05$ ); n, replication number.

cer in Turkish sucuk decreased cholesterol and saturated fatty acid content, but increased polyunsaturated fatty acids in this study. This finding may have implications for meat industry since reduced saturated fat and cholesterol content offer significant health benefits. Moreover, addition of poppy seed oil significantly increased polyunsaturated fatty acids/ saturated fatty acids ratio which will have additional potential health benefits including reduced blood pressure and decreased incidence of cardiac arrhythmias. In addition sensory analysis revealed acceptable results with poppy seed oil replacement. In closing, poppy seed oil as partial animal fat replacer in Turkish sucuk may have significant health benefits without sacrificing its quality characteristics.

\section{Acknowledgements}

This work was supported by Afyon Kocatepe University Research Fund (Project number: 09.MUH.04). We thank Dr. Bülent Ergönül for his valuable contribution in texture analysis.

\section{References}

1. Aksu, M. I. and Kaya, M. (2004) Effect of usage Urtica dioica L. on microbiological properties of sucuk, a Turkish dryfermented sausage. Food Control 15, 591-595.

2. American Heart Association (AHA) (1986) Dietary guidelines for healthy adult Americans. Circulation 74, 1465-1475.

3. Belury, M. A., Moya-Camarena, S. Y., Lu, M., Shi, L. L., Leesnitzer, L. M., and Blanchard, S. G. (2002) Conjugated linoleic acid is an activator and ligand for peroxisome proliferator-activated receptor-gamma (PPAR gamma). Nutr. Res. 22, 817-824.

4. Bloukas, J. G., Paneras, E. D., and Fournitzis, G. C. (1997) Effect of replacing pork backfat with olive oil on processing and quality characteristics of fermented sausages. Meat Sci. 45, 133-144.

5. Bourne, M. C. (1978) Texture profile analysis. Food Technol. 32, 62-66.
6. Bozan, B. and Temelli, F. (2008) Chemical composition and oxidative stability of flax, safflower and poppy seed and seed oils. Bioresource Technol. 99, 6354-6359.

7. Bozkurt, H. (2006) Utilization of natural antioxidants: Green tea extract and Thymbra spicata oil in Turkish dry-fermented sausage. Meat Sci. 73, 442-450.

8. Bozkurt, H. and Bayram, M. (2006) Colour and textural attributes of sucuk during ripening. Meat Sci. 73, 344-350.

9. Chizzolini, R., Zanardi, E., Dorigoni, V., and Ghidini, S. (1999) Calorific value and cholesterol content of normal and low-fat meat and meat products. Trends Food Sci. Tech. 10, 119-128.

10. Choi, Y. S., Choi, J. H., Han, D. J., Kim, H. Y., Lee, M. A, Jeong, J. Y., Chung, H. J., and Kim, C. J. (2010) Effects of replacing pork back fat with vegetable oils and rice bran fiber on the quality of reduced-fat frankfurters. Meat Sci. 84, 557563.

11. COMA (1984) Committee on the medical aspects of food policy, diet and cardiovascular disease. London: Department of Health and Social Society.

12. Ercoskun, H., Tagi, S., and Ertas, A. H. (2010) The effect of different fermentation intervals on the quality characteristics of heat-treated and traditional sucuks. Meat Sci. 85, 174-181.

13. Erinc, H., Tekin, A., and Ozcan, M. M. (2009) Determination of fatty acid, tocopherol and phytosterol contents of the oils of various poppy (Papaver somniferum L.) seeds. Grasas $Y$. Aceites 60, 375-381.

14. Gök, V., Akkaya, L., Obuz, E., and Bulut, S. (2011) Effect of ground poppy seed as a fat replacers on meat burgers. Meat Sci. 89, 400-404.

15. Gök, V., Obuz, E., and Akkaya, L. (2008) Effects of packaging method and storage time on the chemical, microbiological, and sensory properties of Turkish pastirma - A dry cured beef product. Meat Sci. 80, 335-344.

16. Gökalp, H.Y., Kaya, M., and Zorba, Ö. (1999) Engineering of Meat Products Processing. 3RD ed. Atatürk University, Faculty of Agriculture, Food Engineering Department, Erzurum, Turkey. 457 p. (In Turkish)

17. Ilikkan, H., Ercoskun, H., Vural, H., and Sahin, E. (2009) The effect of addition of hazelnut oil on some quality characteristics of Turkish fermented sausage (Sucuk). J. Muscle Foods 20,117-127. 
18. Imaizumi, K., Adan, Y., and Shibata, K. (2000) Role of dietary lipids in arteriosclerosis in experimental animals. Biofactors 13, 25-28.

19. Kayaardi, S. and Gok, V. (2004) Effect of replacing beef fat with olive oil on quality characteristics of Turkish soudjouk (sucuk). Meat Sci. 66, 249-257.

20. Muguerza, E., Gimeno, O., Ansorena, D., Bloukas, J. G., and Astiasaran, I. (2001) Effect of replacing pork back fat with pre-emulsified olive oil on lipid fraction and sensory quality of Chorizo de Pamplona - a traditional Spanish fermented sausage. Meat Sci. 59, 251-258.

21. Muguerza, E., Fista, G., Ansorena, D., Astiasaran, I., and Bloukas, J. G. (2002) Effect of fat level and partial replacement of pork back fat with olive oil on processing and quality characteristics of fermented sausages. Meat Sci. 61, 397-404.

22. Naeemi, D. E., Ahmad, N., Al-Sharrah, T. K., and Behrahania, M. (1995) Rapid and simple method for determination of cholesterol in processed foods. J. AOAC Int. 78, 1522-1525.

23. Naga Mallika, E. and Prabhakar, K. (2011) Physico-chemical properties of low fat pork sausages. AEJAES 10, 160-162.

24. NCEP (1988) The effect of diet on plasma lipids, lipoproteins and coronary heart disease. J. Am. Diet Assoc. 88, 1373-1400.

25. Nergiz, C. and Ötles, S. (1994) The proximate composition and some minor constituents of poppy seeds. J. Sci. Food Agr. 66, 17-120.

26. Özvural, E. B. and Vural, H. (2008) Utilization of interesterified oil blends in the production of frankfurters. Meat Sci. 78, 211-216.

27. Rongrong, L., Carpenter, J. A., and Cheney, R. (1998). Sen- sory and instrumental properties of smoke sausages made with technically separated poultry (MSP) meat and wheat protein. J. Food Sci. 63, 923-929.

28. SAS (2001) SAS user's guide. Cary, NC: SAS Institute, Inc.

29. Severini, C., De Pilli, T., and Baiano, A. (2003) Partial substitution of pork backfat with extra-virgin olive oil in 'salami' products: effects on chemical, physical and sensorial quality. Meat Sci. 64, 323-331.

30. Shahidi, F. (2000). Antioxidant factors in plant foods and selected oilseeds. Biofactors 13, 179-185.

31. Shahidi, F., Yun, J., Rubin, L. J., and Wood, D. F. (1987). The hexanal content as an indicator of oxidative stability and flavor acceptability in cooked ground pork. Food Res. Int. 20, 104-106.

32. Simopoulos, A. P. (1997) x-3 fatty acids in the preventionmanagement of cardiovascular disease. Can. J. Physiol. Pharm. 75, 234-239.

33. Soyer, A., Ertas, A. H., and Uzumcuoglu, U. (2005). Effect of processing conditions on the quality of naturally fermented Turkish sausages (sucuks). Meat Sci. 69, 135-141.

34. Turkish Food Codex (2000) Communique on Fresh Meat, Prepared Meat and Prepared Meat Mixtures. The Official Gazette: 10.02.2000-23960, Communication No: 2000/5.

35. Wijendran, V. and Hayes, K. C. (2004) Dietary n-6 and n-3 fatty acid balance and cardiovascular health. Annu. Rev. Nutr. 24, 597-615.

36. Yildiz-Turp, G. and Serdaroglu, M. (2008). Effect of replacing beef fat with hazelnut oil on quality characteristics of sucuk - A Turkish fermented sausage. Meat Sci. 78, 447-454. 